\title{
A Psicanálise não é uma Ciência. Mas, Quem se Importa?
}

Este artigo aborda a Psicanálise dentro de seu contexto histórico-científico, discute questões sobre sua cientificidade e observa algumas conseqüências decorrentes dos rumos tomados pelo saber psicanalítico durante o último século. Ao final, é realizada uma articulação conclusiva sobre os fatores que intervêm no contexto proposto, levando em conta a necessidade ou não de a Psicanálise adquirir o estatuto de Ciência.

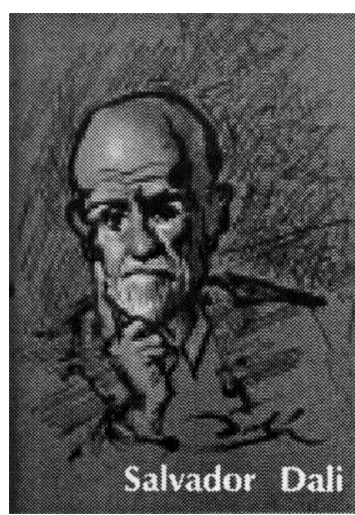

Roberto Henrique Amorim de Medeiros

Psicólogo e aluno do Curso de Especializoçōo em Psicoterapia Individual Psicanalitica da Clínica de Atendimento Psicológico da UFRGS

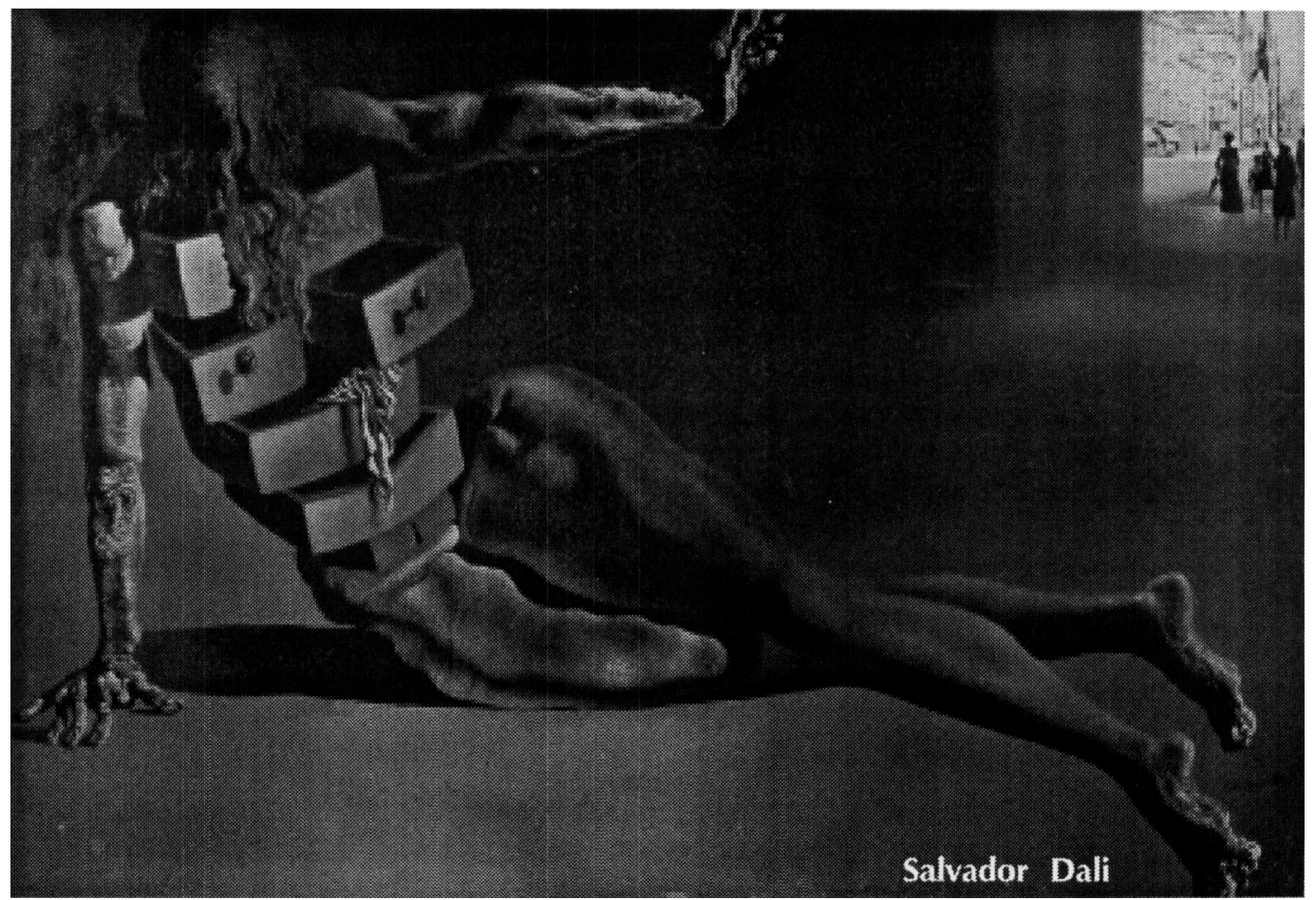

Transcorria o séc XV e o conhecimento humano, até então, era baseado apenas nas tradiçōes sociais da época e, principalmente, na filosofia religiosa da Igreja Católica.

Foi apenas ao final desse mesmo século, com os acontecimentos que solaparam a visão tradicional, como as guerras, os descobrimentos pela navegação e as reformas sociais, que o homem sentiu a necessidade de apoiar seu conhecimento em novos alicerces. Os antigos estavam por demais insuficientes. Como dizia Aristóteles, a tradição não é nociva e sim a comodidade.

Essa necessidade premente teve como seu resultado maior, em decorrência da disciplina do método, a formulação do cogito cartesiano. Nele, assume-se, entre outras coisas, que o espírito seria mais fácil de conhecer do que o corpo, num claro processo de priorização da subjetividade. A verdade só poderia ser seguramente atingida separando-se os sentidos de seus afetos e paixões, isto é, pei: razão. 
É por essa via que aquilo que conhecemos hoje em dia como Ciência se estruturou e quando o séc XIX chegou ao seu final, o dr. Sigmund Freud elaborava a construção de um novo conhecimento respeitando as mesmas regras e noçōes inauguradas por Descartes. A intenção de Freud de criar uma nova disciplina científica já era clara nessa época.

No entanto, o novo conhecimento professado pelo médico vienense, embora de acordo com uma infinidade de outros pensadores que voltavam a sua atenção para os fenômenos que iriam se chamar inconscientes, trazia o problema de como tornar inteligível ou palpável os seus conceitos, respeitando, assim, o paradigma científico.

O saber filosófico do séc XIX, norteado pelo Romantismo, já trazia através de alguns pensadores, as principais noções que seriam utilizadas posteriormente por Freud na construção daquilo que se chamou Psicanálise. Esse contexto, no qual estava inserido Freud e a sua busca pela cientificidade de sua teoria, fez com que se iniciasse sua relação de amor e desprezo com a filosofia. Em sua obra e biografia, podemos encontrar duas facetas do autor. Aquele Freud que, embevecido com as maravilhas do conhecimento humano, faz um resumo de filosofia básica para sua esposa é o mesmo Freud que se declara um ignorante nessa área ou que desconhece teorias filosóficas em estreito acordo com as suas.

A busca, diria frenética, de tornar a Psicanálise uma ciência parece justificar essas e outras atitudes. Freud irá escrever o Projeto, texto no qual, através do modelo mecanicista da Física - a ciência com $\boldsymbol{C}$ maiúsculo - tentará expor seus conceitos. Com sua obra, Freud tenta demonstrar empiricamente o que a filosofia do final do século passado abordava intuitivamente.

Ao que parece, cem anos passados, Freud entregou-se a uma tarefa complicada ao extremo. Com o desenvolvimento de sua ter : ia através de suas observações clínicas, o caráter fisicalista que tentava impor à Psicanálise foi-se tornando insuficiente. Embora nunca tendo demonstrado uma rendição ao fato de que seus modelos físicos jamais poderiam dar conta de toda especificidade da ordem psíquica, Freud vêse obrigado a escrever artigos que chamou metapsicológicos. Porém, nem nesses artigos e muito menos neles, encontramos sequer uma renúncia ao modelo fisicalista, embora isso conviva com afirmaçōes como as concernentes à pulsão, que se situa entre o físico e o psíquico, constituindo-se num postulado no mínimo estranho à ciência como tal.

O que emerge de toda essa situação é o conflito resultante do desejo cientificista de Freud e de sua impossibilidade que deriva da própria especificidade do conhecimento que ele construiu.

Apesar de tudo, a Psicanálise sobreviveu a todas as críticas, mas a vontade inicial do mestre Freud parece ter encontrado morada nos seus seguidores. Por outro lado, epistemólogos também não pararam de elaborar teorizações e argumentos para a questão da validação do saber psicanalítico como ciência. Modestamente, é digno de nota que até eu me encontro em tarefa semelhante no momento em que escrevo este texto.

Se a Psicanálise não é uma ciência, pelo menos deve ser algo muito curioso e instigante, longe de ser um absurdo. Prova disso é exatamente o fato de nunca ser esquecida essa discussão. De um lado encontramos os positivistas e seus preceitos de que uma ciência deve ter proposições claras onde se possa predizer todo tipo de ocorrência de fenômenos ou, então, a idéia popperiana de que uma teoria, para ser científica, deveria prever em que momento poderia ser refutada. Todos esses e outros aspectos não são observáveis em Psicanálise.
A tradição não é nociva e sim a comodidade.

Aristóteles 
Do outro, encontramos uma infinidade de seguidores de Freud, inclusive Lacan, tentando contrargumentar em favor da concepção de que a Psicanálise é uma ciência.

Acerca dessa tentativa dos psicanalistas, vemos a teoria freudiana receber novas leituras. Do mentalismo de Freud passa-se ao estruturalismo lacaniano. Da concepção pulsional passa-se à paradigmática e todas, elas em algum momento, tocam na delicada questão que aqui se coloca afirmando uma possível solução para a mesma. Porém, essa solução é sempre da mesma ordem e os discípulos de Freud parecem inexoravelmente

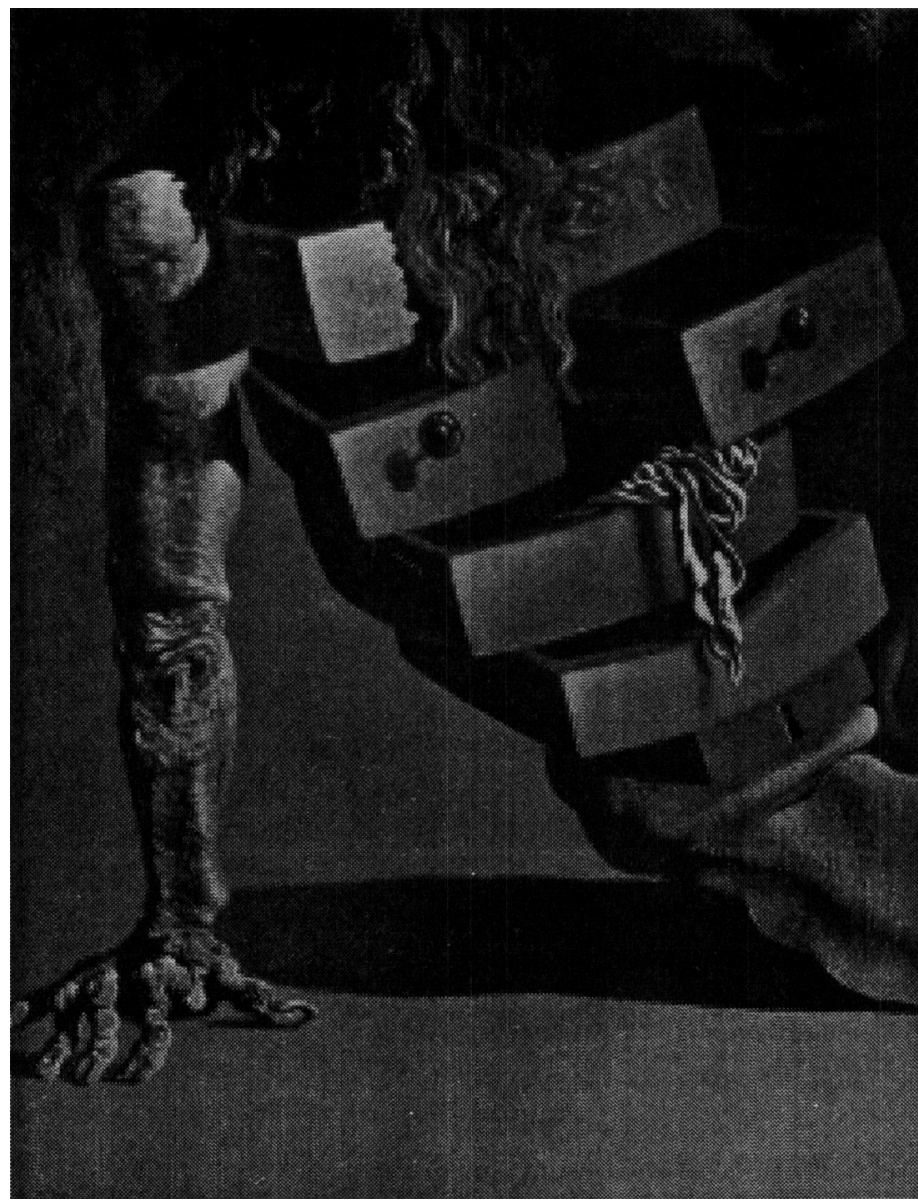

presos às mesmas aspiraçōes do mestre em detrimento do fato de que, seja qual forem as epistemologias que tratam da cientificidade da Psicanálise, seja qual for o dispositivo que usem para a validação de uma teoria como
Ciência, nada poderá conceber a teoria freudiana como uma disciplina científica.

O positivismo da ciência vigente jamais poderia conviver com o que se chama de desvio especulativo da Psicanálise que deu origem a idéias como a da pulsão, id, ego e superego. $O$ freqũente uso de metáforas impediria uma delimitação de seus usos e o próprio fato de que qualquer fenômeno pode ser referido a um construto psicanalítico vem provar que a Psicanálise não tem um conteúdo empírico próprio. A a-falseabilidade da teoria freudiana onde qualquer resultado contraditório pode ser interpretado segundo a própria teoria e a incomensurabilidade do modelo energético pulsional engendrado por Freud são alguns dos tantos exemplos que colocam barreiras à intenção científica da Psicanálise.

Porém, como disse ao iniciar este texto, minha proposta não é - e nem poderia ser, dado o grau de complexidade e dimensão deste trabalho - avaliar os prós e contras da questão que aqui é abordada, mas de trazer uma opinião que passo a descrever neste momento.

Em primeiro lugar, observaria o seguinte: diante do que se conclui até o momento, é verdade que, através do estudo epistemológico, a Psicanálise não poderia em nenhuma hipótese adquirir o status de Ciência, por seu objeto de estudo, sua forma etc. No entanto, gostaria de chamar atenção ao fato de que, até hoje, a Ciência - com o $C$ maiúsculo - pouco disse ou explicou os fenômenos psíquicos, que também não podem ser simplesmente negados. Por outro lado, a Psicanálise, teoria que mais se aproximou do conhecimento científico nesta área, é bem verdade, também não logra êxito satisfatório nessa tarefa.

Até os dias de hoje, as já citadas releituras da teoria de Freud estão cada vez mais em voga e, se não alcançam totalmente seu objetivo de resgate, é inegável que o qua 
conseguiram, entre outras coisas, foi um progressivo esvaziamento do ser - que com o conceito de divisão do sujeito fica impossibilitado de qualquer conhecimento sobre sua essência, sendo ali mesmo onde não pode ser, como costumava dizer Lacan e um deslocamento do inconsciente, pedra de toque freudiana, para um plano secundário no momento em que é evidenciado apenas seu aspecto patológico ou de material recalcado.

Diante disso, uma conclusão, pelo menos, parece ser possível. É justamente o fato de que, talvez, a Ciência, com suas peculiaridades, suas normas e convenções, não pode dar conta de fenômenos de uma natureza psíquica em sua totalidade. Não esqueço aqui de todos os avanços na área biológica da neurofisiologia que ocorreram no último século e que vieram lançar luz sobre muitas questões referentes à dinâmica cerebral dos neurotransmissores e à própria doença mental. Entretanto, o excesso de generalizações e reducionismos que a concepção biologicista traz acaba tornando esse conhecimento igualmente insuficiente diante da riqueza das especificidades com que nos deparamos quando tratamos do funcionamento psíquico humano.

Caricaturalmente poder-se-ia dizer que, desde que a filosofia cartesiana priorizou a razão, todos dali em diante passaram a querer tê-la de maneira exclusiva. No que se refere ao psiquismo cada saber reclama para si a verdade. Como já foi dito, os avanços atuais das neurociências, principalmente na área dos psicofármacos, trazem argumentos fortíssimos que desequilibram a balança da razão para seu lado. No outro, infelizmente, vemos a Psicanálise - e com ela a Psicologia mantendo-se apenas porque a biologia não demonstra ser completamente eficaz. Chegase à mesma questão do parágrafo anterior.

Por que isso acontece? Certamente seria difícil responder em poucas linhas. Mas, a título de questão a ser refletida com maior profundidade em outro momento, não seria plausível pensar que a Psicanálise, quando da tentativa de assemelhar-se a um paradigma científico que servia muito bem

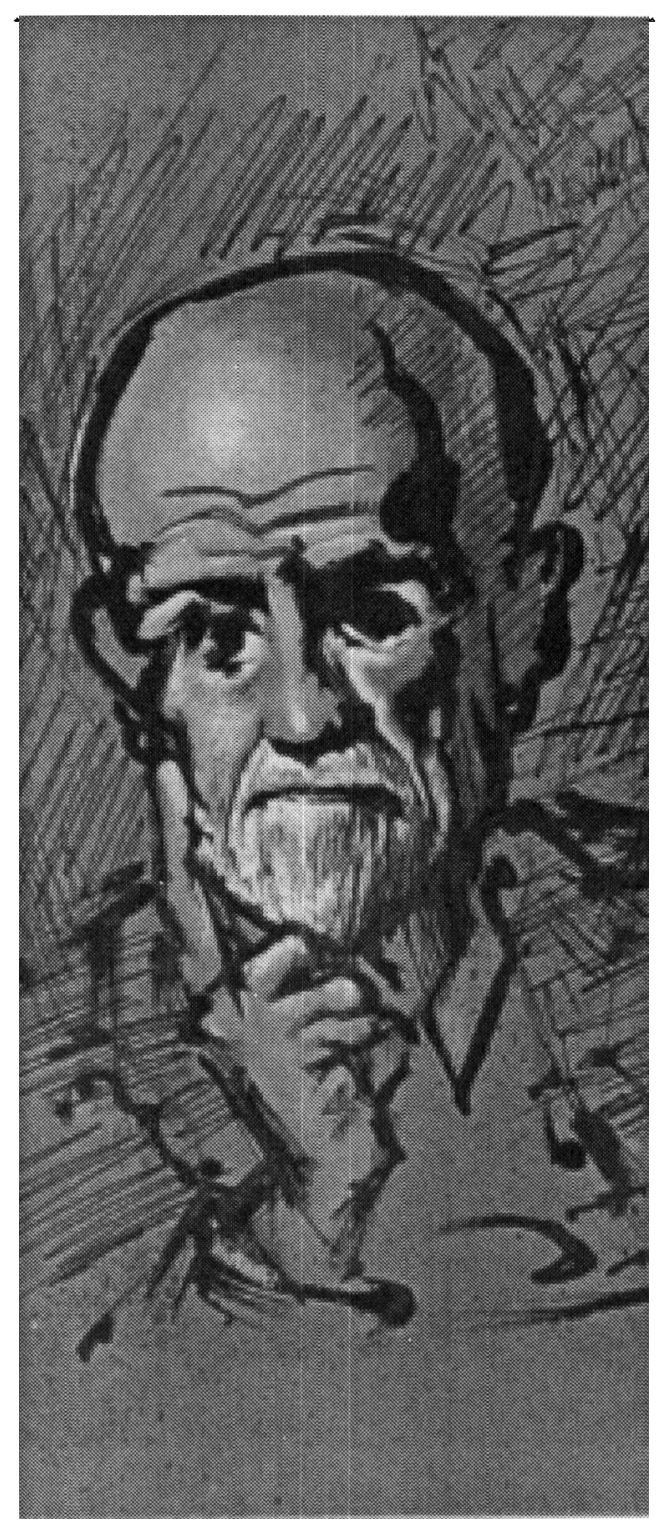

às ciências ditas naturais, perdeu aquilo que poderia ser sua especificidade no entendimento de algo tão inexato como a psiquê? Que preço terá pago Freud - e com ele todos os psicanalistas - pela sua vontade narcísica de ser o inventor de um novo saber científico? Muito poderia ser especulado
Que preço teró

pago Freud - e

com ele todos os

psicanalistas - pela

sua vontade

narcísica de ser o

inventor de um novo

saber cientifico? 
acerca da primeira interrogação e talvez a teoria de Adler fosse útil para pensarmos a segunda.

De qualquer forma, quando considero a Ciência vigente, cartesiana por excelência e por séculos a fio, novamente me vem à mente a velha afirmação de Aristóteles sobre a tradição. $O$ quanto talvez não estejamos acomodados à tradição científica e fechamos os olhos a fenômenos que acomodadamente

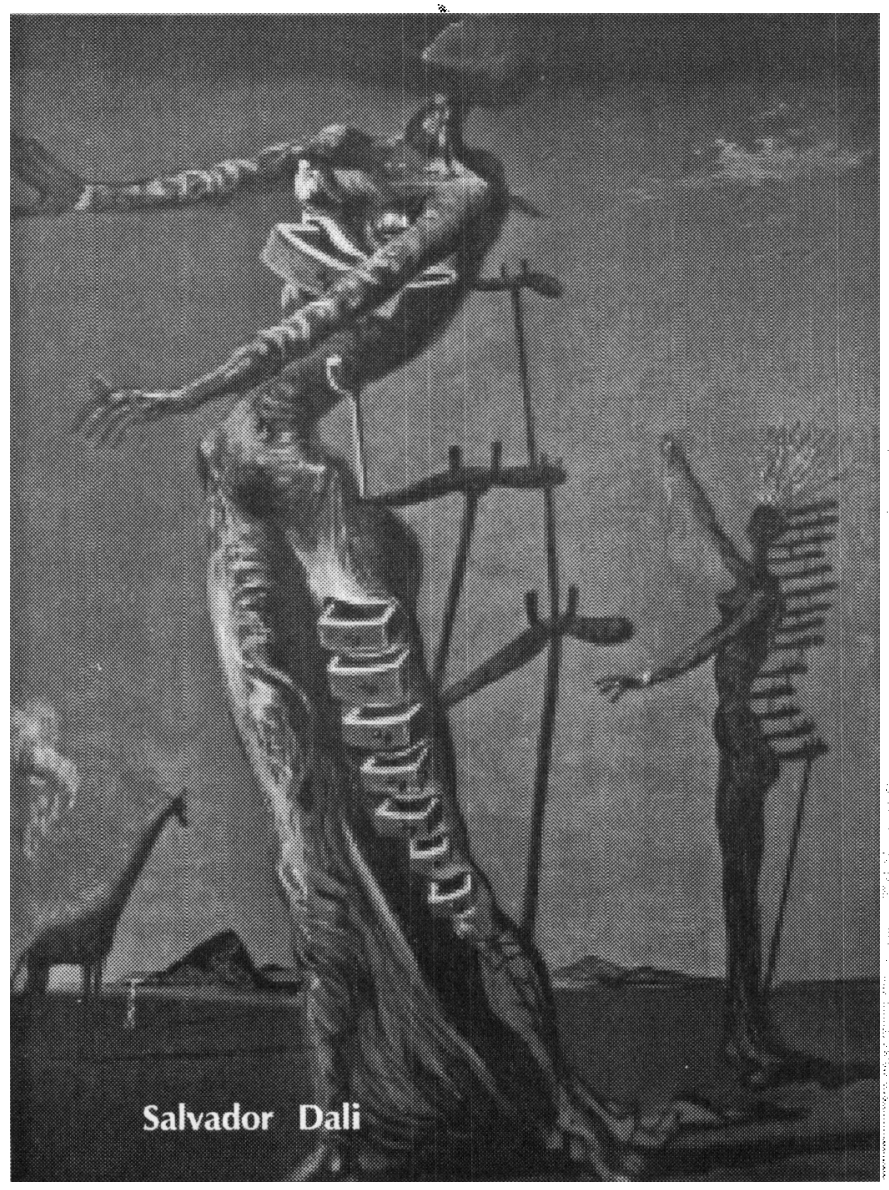

tachamos de místicos e deixamos de lado, ao passo que parece que sabemos cada vez menos sobre nós mesmos.

Penso que a Psicanálise não ganharia em nada sendo uma Ciência. Por vezes até perderia. O fato de não ser uma ciência jamais a destituirá de um significado ou de constituir um saber pertinente e que produz resultados na clínica.
Se é a psicanálise um saber, uma hermenêutica, uma ética ou apenas uma técnica, isso pouco importa, principalmente se levarmos em conta o motivo pelo qual ela foi criada um dia. O paciente que chega ao psicólogo ou psicanalista vem em busca de um alívio, seja qual for a ordem. $E$, nesse momento, o que interessa é que o método psicanalítico seja útil e se mostre de alguma valia.

Mesmo levando em consideração o valor da motivação gerada pelo ideal cientificista na pesquisa e na obra de Freud, volta-me a questão do preço pago pela Psicanálise na tentativa frustrada de adaptação à ciência vigente - vide o Projeto, obra inacabada. Frente a fatos como esse e os que se seguiram após Freud, parece poder ser útil se pensar em uma mudança de foco do objeto psicanalítico ou, mais radicalmente, a adoção de um novo paradigma que permita um livre trânsito das observações igualmente empíricas na construção de novas teorizações, longe das amarras do método científico atual.

Talvez, seria realmente demasiado esperar que Freud - que com sua teoria sexual já havia balançado as bases morais da sociedade da época - fosse, ainda, polemizar com os defensores do conhecimento científico ao propor essa mudança de paradigma logo de início.

A Psicanálise nāo se tornou uma Ciência e Freud hoje em dia talvez nem se importasse mais com isso, pois atualmente ela ocupa um lugar respeitado em seu meio. Por que ainda nos importamos? 
Assoun, PL. (1978) Freud, a filosofia e os filósofos. Rio de Janeiro: Francisco Alves.

Birman, J. (1994) Os impasses da cientificidade no discurso freudiano. In: Psicanálise, ciência ecultura. Rio cue Janeiro: Zahar.
Freud, S. Pulsóes e destinos da pulsāo (1915). In: Obras completas; Edição standard brasileira. Rio de Janeiro: Imago. v. 14.

Palombini, A. (1996) Fundamentos para uma crítica da epistemologia da psicanálise. Dissertação de Mestrado em Filosofia UFRCS, defendida em julho de 1996; Porto Alegre - Brasil.

Referências bibliográficas 